\title{
EFFECT OF NATURAL ADDITIVE (BEE POLLEN) AS ALTERNATIVES FOR ANTIBIOTIC ON THE STRENGTH TIBIAL BONES, ILEAL MORPHOLOGY AND SELECTED BLOOD PARAMETERS IN BROILER CHICKENS
}

\section{M.M. Hamed, A.I. El-Faham, F. Abd El-Azeem, and M.E. El-Medany}

Poultry Production Department, Faculty of Agriculture, Ain Shams University, Cairo, Egypt

In today's broiler production, there is ban of antibiotic growth promoters (AGPs), and a tendency for development of antibiotic-free productions associated with a reduced usage of antimicrobial treatment. On-farm basis, there are common trends towards a more responsible use of antibiotics. Therefore, many researchers tried to find some natural feed additives such as Beepollen (BP) to be an effective natural alternative to (AGPs) for improving production performance without negative effects on poultry health and welfare, human health or the environment.

This study compared effects of using antibiotic (Colistin sulphate, CS) and BP in broiler chickens fed corn-soybean-based diets with examining some tibia measurements, ileal morphology and selected blood parameters.

A total of 150 one-day Cobb 500 broiler chicks, was randomly assigned to five treatments including experimental groups, three replicates of ten chicks each. A basal diet (control) was supplemented with $100 \mathrm{~g} \mathrm{CS/} \mathrm{Ton,} \mathrm{T1,} \mathrm{while,T2:} \mathrm{T4,} \mathrm{were} \mathrm{formulated} \mathrm{as} \mathrm{basal} \mathrm{diet} \mathrm{supplemented}$ with 500, 1000 and $2000 \mathrm{~g} \mathrm{BP} /$ Ton respectively. At 35 days of age (end of experiment), tibia bone measurements (wet tibia weight, tibia length, tibia width, tibia Seeder index and tibia breaking strength) showed insignificant differences within dietary treatments. Also, no differences were observed for digestive tract length. On the other hand, villus (height and width), muscle thickness and goblet cell count were significantly different for tested groups. There were no significant differences in bursa or spleen weight percentage.

Interestingly, the addition of either 1000 or $2000 \mathrm{~g} \mathrm{BP/Ton} \mathrm{decreased} \mathrm{blood} \mathrm{plasma}$ cholesterol, triglyceride, AST or ALT and increased total protein and globulin, whereas other biochemical parameters; albumin, calcium and phosphorus concentration were not changed compared with those fed control diet, and, in most cases, differences were significant. In conclusion, Bee-pollen supplementation to broiler diets had a significant positive effect on villus development and therefore, better activity of digestion and/or absorption, with decreased plasma cholesterol, triglycerides and increased total protein and globulin concentrations without any adverse effect on tibia bone criteria of broilers. 